\title{
A Series of Awake Craniotomy Procedures Performed in Iran
}

\author{
Kamran Mottaghi, ${ }^{1}$ Armin Nowroozpoor, ${ }^{2}$ Farhad Safari, ${ }^{1}$ Alireza Salimi, ${ }^{3}$ and Masoud Nashibi ${ }^{4,}$ \\ ${ }^{1}$ Associate Professor of Anesthesiology, Shahid Beheshti University of Medical Sciences, Tehran, IR Iran \\ ${ }^{2}$ General Practitioner, Shahid Beheshti University of Medical Sciences, Tehran, IR Iran \\ ${ }^{3}$ Professor of Anesthesiology, Shahid Beheshti University of Medical Sciences, Tehran, Iran \\ ${ }^{4}$ Assistant Professor of Anesthesiology, Shahid Beheshti University of Medical Sciences, Tehran, IR Iran \\ "Corresponding author: Masoud Nashibi, Assistant Professor of Anesthesiology, Shahid Beheshti University of Medical Sciences, Tehran, IR Iran. Tel/Fax: +98-2155424040, \\ E-mail: masoudnashibi@sbmu.ac.ir
}

Received 2016 September 06; Revised 2016 December 21; Accepted 2016 December 24.

\begin{abstract}
"Awake craniotomy" is a technique used in neurosurgical procedures, commonly performed to remove a tumor or an epileptogenic focus while the patient is awake. There has been an increasing trend towards performing this type of procedure because of its advantages; above all, the ability to map the eloquent cortex to reduce post-surgical neurological sequel. The aim of this article is to introduce 8 cases of awake craniotomies, performed in Loghman-e-Hakim hospital in Tehran, Iran. Patients were selected according to our specific criteria. Oral clonidine ( $4 \mu \mathrm{g} / \mathrm{kg}$ ), dexamethason ( $8 \mathrm{mg} / \mathrm{IV})$, midazolam ( $0.03 \mathrm{mg} / \mathrm{kg} / \mathrm{IV})$, and sufentanil ( $3 \mu \mathrm{g} / \mathrm{kg} / \mathrm{IV})$ were used as premedication. Patients underwent cerebral state monitoring and other monitoring modalities during the procedure. A laryngeal mask was used during the asleep phase of the anesthesia. General anesthesia was induced using propofol and lidocaine. Local anesthesia was provided with bupivacaine in the incision and pin insertion sites. Anesthesia was maintained using propofol and remifentanil infusion. A total of 8 patients underwent the procedure. No significant complications, including hemodynamic instability, depressed respiration, the need to put the patient to sleep before mapping or tumor resection, intraoperative seizures, aspiration, and brain edema were observed in any of our patients. In conclusion, we believe that a modified asleep-awake-awake technique instead of the asleep-awake-asleep technique may provide less complications and less need to manage the patients' airway.
\end{abstract}

Keywords: Awake Craniotomy, Anesthesia

\section{Introduction}

Awake craniotomy has been used in various neurosurgical procedures, including seizure surgery and tumor resection in eloquent regions. The purpose of this procedure is to provide intraoperative brain mapping of functionally important areas of the brain, namely the motor, sensory, and speech cortices, to minimize the risk of damaging these areas and thus decreasing neurological deficits and also decreasing intensive care time and hospital stay (1-10).

Different anesthetic methods have been used for this type of procedure $(1,5,11-19)$. The asleep-awake-asleep method is one of the most widely used techniques $(5,20)$. It comprises 3 phases. In the first phase, the patient's airway is usually maintained using a laryngeal mask or a tracheal tube, local anesthesia is provided to the scalp and general anesthesia is initiated after which the craniotomy is performed. During the second phase the patient is awakened, the eloquent cortex is mapped and the tumor/lesion is resected. In the third phase, the patient is put to sleep again, and the cranium is closed.

We report 8 successful cases of awake craniotomies since 2008; the earliest to be done in Iran (2). The patients were admitted to Loghman-e-Hakim hospital in Tehran, Iran. Our approach consisted of a modification, which kept the patients awake in the third stage instead of putting them back to sleep.

The goal of the anesthesiologist is to initiate and maintain an adequate level of sedation and analgesia during the procedure and to allow the patient to be able to cooperate with the surgeon while mapping the cortex. It is also critical to manage the airway properly and to monitor patient's hemodynamic status $(13,18,21)$.

\section{Methods}

\subsection{Technique}

Each institution uses different criteria to select patients. The exclusion criteria used for selecting patients at this institution are outlined in the Table $1(3,22)$.

All patients were interviewed prior to the operation. The procedure was explained in detail to each patient and their compliance was subjectively assessed by the corresponding anesthesiologist and neurosurgeon. Most of the selected patients had lesions in the frontal or parietal lobe, which could be operated in supine position. 


\begin{tabular}{ll}
\hline Table 1. Exclusion Criteria \\
\hline \multicolumn{1}{l}{ Exclusion Criteria } \\
\hline - & Languages other than Farsi or other dialects of Farsi as patient's primary \\
& language \\
- & Confused patient \\
\hline - & Communication difficulties \\
\hline - & Extreme anxiety \\
\hline - & Low occipital tumor (prone position) \\
\hline - & Significant dural involvement (painful) \\
\hline - & Inability to lie still for many hours \\
\hline - & Inexperienced surgeon \\
\hline - & Patients with mental retardation \\
\hline - & Younger children \\
\hline - & Very large tumors \\
\hline - & Difficult airway \\
\hline & History of Gastro-esophageal reflux(regurgitation) \\
\hline
\end{tabular}

At our hospital, we used oral clonidine with a dose of 4 $\mu \mathrm{g} / \mathrm{kg}$ thirty minutes before surgery, and midazolam with a dose of $0.03 \mathrm{mg} / \mathrm{kg}$ and sufentanil of $0.3 \mu \mathrm{g} / \mathrm{kg}$ as premedication. Intravenous dexamethasone $(8 \mathrm{mg})$ started soon after admission to the operating room in order to decrease the edema and inflammation of brain tissue and to also decrease the likelihood of emesis during procedure. All patients received an anticonvulsant (Phenytoin $750 \mathrm{mg} / \mathrm{IV} /$ infusion) for seizure prophylaxis and IV mannitol $0.25 \mathrm{~g} / \mathrm{Kg}$ to decrease intracerebral pressure.

All patients were monitored for temperature, blood pressure (using noninvasive blood pressure monitoring), pulse rate, $\mathrm{O}_{2}$ saturation level (using pulse-oximetry), endtidal $\mathrm{CO}_{2}$, electrocardiography, cerebral state monitoring (CSM), and urinary output. An arterial line was placed in all patients after induction of anesthesia and blood pressure was being monitored beat to beat.

General anesthesia was induced using $2 \mathrm{mg} / \mathrm{kg}$ propofol and $1 \mathrm{mg} / \mathrm{kg}$ lidocaine. Airway was managed using a properly sized laryngeal mask airway (LMA). We did not perform nerve block for any of the patients but did provide local anesthesia by injection of $0.5 \%$ bupivacaine, a longacting local anesthetic, in the incision and pin insertion sites.

Anesthesia was maintained using a propofol infusion at a rate of $100-300 \mu \mathrm{g} / \mathrm{kg} / \mathrm{min}$ and remifentanil at a rate of $0.1 \mu \mathrm{g} / \mathrm{kg} / \mathrm{min}$ to keep the depth of anesthesia between 40 and 60 on the CSM scale. Tidal volume and respiratory rate were set to keep the peak airway pressure below $15 \mathrm{cmH}_{2} \mathrm{O}$ and the end-tidal $\mathrm{CO}_{2}$ between 35 - $40 \mathrm{mmHg}$.
In order to awaken the patients, the propofol and remifentanil infusions were discontinued followed by waiting until the patients fully woke up, the CSM displayed a depth of 94 or more, and spontaneous ventilation had a regular pattern.

During mapping of the regions of the cortex, the medical team talked to the patient continuously, asked questions and gave different orders (e.g. moving an extremity) to assess patient's articulation, motor movements, and muscle tone.

During closure of the dura and cranium, unlike the established method of asleep-awake-asleep, we kept the patients awake. Since there was no dural involvement in our cases and the tumors were mostly located in the frontal and parietal lobes, dural closure was pain free. If the patients experienced pain during the skin closure, the surgeon administered a local anesthetic infiltration.

\subsection{Patients}

\subsubsection{Case 1}

A 38-year-old male patient, with a history of refractory seizures since the age of 7 , was presented to the neurology department. The patient had simple focal seizures with preceding aura which then proceeded to general tonic-clonic seizures. The patient was on a regimen of 6 antiepileptic drugs. The seizures mostly occurred during his sleep, although did increase in frequency since 6 months after which they occurred as many as 3 times a day while the patient was awake. The corresponding cortex was diagnosed by Magnetic Resonance Imaging (MRI), which was shown to be adjacent to the motor cortex. He underwent awake craniotomy with mapping and removal of the pathologic tissue.

He was discharged 15 days after the procedure, and at the time of writing this article, was on 2 antiepileptic drugs and had no recurrence of seizures.

\subsubsection{Case 2}

A 34-year-old female patient with a history of generalized tonic-clonic seizures since 5 years ago was admitted to the neurology department. The patient was being treated with carbamazepine and her seizures were under control, having simple partial seizures limited to the face. However, the frequency of the seizures increased since last year and did not respond to changes in medication.

On the computed tomography (CT) imaging performed, a hypodense lesion in the right frontal area with compression on the lateral ventricle, suggestive of oligodendroglioma, was noted.

She tolerated awake craniotomy and the lesion was completely excised with no collateral damage to eloquent 
cortices. Hereafter, she was discharged with a minimal dose of anticonvulsants and is seizure free.

\subsubsection{Case 3}

The patient was a 23 year-old- male with a history of tonic-clonic seizures since the age of 8 . The patient had been on different regimens of anticonvulsive drugs with no significant improvement.

The MRI showed a lesion in the left frontal (premotor) cortex, suggestive of a dysembryoplastic neuroepithelial tumor.

As the other cases, he successfully tolerated awake craniotomy without experiencing any pain during the dural and skin closures.

\subsubsection{Case 4}

A 39-year-old male with a history of sudden right-sided hemiparesis, seizures, headaches, and vertigo one month prior to the procedure, was admitted.

On the CT scan performed, an isodense lesion in left frontoparietal area, suggestive of glioblastoma, was observed.

\subsubsection{Case 5}

A 29-year-old woman with a previous history of two surgeries for high-grade glial tumor (gliablastoma multiforme) in the past year was admitted with a diagnosis of relapse of the tumor and symptoms.

On the CT scan, a residual tumor in the right parietal lobe with a midline shift and pressure effect on the ventricular system was visible.

She underwent awake craniotomy. The procedure did not have any significant complications but due to nature of the tumor, she unfortunately passed away later that year.

\subsubsection{Case 6}

A 38-year-old man with a history of recent-onset generalized tonic clonic seizures, dementia episodes, and headaches was admitted.

The imaging revealed a tumor in the left occipitotemporal region, suggestive of an oligodendroglioma.

The patient underwent awake craniotomy and complete tumor excision. He is now symptom-free without any relapses and has an acceptable quality of life.

\subsubsection{Case 7}

A 32-year-old man suffering from left hemiparesis and seizures, was admitted in 2010.

On the imaging, a cystic mass in the right parietal lobe with $\mathrm{T} 1$ and $\mathrm{T} 2$ enhancement, suggestive of a cavernous hemangioma, was found.
After the surgery, he received sodium valproate for three years as seizure prophylaxis. He had no episodes of seizures after the procedure, and all medications were discontinued after three years. The hemiparesis was considerably resolved and he was able to perform daily activities without any difficulty.

\subsubsection{Case 8}

A 19-year-old woman, who had been experiencing seizures since she was 4 months old as well as having a transient right upper limb paralysis, was admitted. She had been under medical treatment since the start of her seizures, however, with limited success.

On the CT scan there was a huge low attenuation area in left frontal lobe without any mass effect or shift in brain tissue. The MRI was suggestive of encephalomalacia. She also underwent uneventful awake craniotomy, resulting in resolution of the paralysis and seizures and no relapse of symptoms (Table 2 ).

Table 2. Brief Presentation of Cases

\begin{tabular}{|c|c|c|c|}
\hline Case Number & Presentation & Technique & Outcome \\
\hline $\mathbf{1}$ & $\begin{array}{l}\text { Refractory } \\
\text { seizure }\end{array}$ & $\begin{array}{l}\text { Asleep-awake- } \\
\text { awake }\end{array}$ & $\begin{array}{l}\text { Seizure free, no } \\
\text { motor damage }\end{array}$ \\
\hline 2 & $\begin{array}{l}\text { Refractory } \\
\text { seizure }\end{array}$ & $\begin{array}{l}\text { Asleep-awake- } \\
\text { awake }\end{array}$ & $\begin{array}{l}\text { Seizure free, no } \\
\text { motor damage }\end{array}$ \\
\hline 3 & $\begin{array}{l}\text { Refractory } \\
\text { seizure }\end{array}$ & $\begin{array}{l}\text { Asleep-awake- } \\
\text { awake }\end{array}$ & $\begin{array}{l}\text { Seizure free, no } \\
\text { motor damage }\end{array}$ \\
\hline 4 & $\begin{array}{l}\text { Hemiparesis, } \\
\text { Seizures }\end{array}$ & $\begin{array}{l}\text { Asleep-awake- } \\
\text { awake }\end{array}$ & $\begin{array}{l}\text { Seizure free, no } \\
\text { motor damage }\end{array}$ \\
\hline 5 & $\begin{array}{l}\text { Relapse of the } \\
\text { tumor }\end{array}$ & $\begin{array}{l}\text { Asleep-awake- } \\
\text { awake }\end{array}$ & $\begin{array}{l}\text { Complete tumor } \\
\text { excision }\end{array}$ \\
\hline 6 & $\begin{array}{l}\text { Seizures, } \\
\text { dementia }\end{array}$ & $\begin{array}{l}\text { Asleep-awake- } \\
\text { awake }\end{array}$ & $\begin{array}{l}\text { Complete tumor } \\
\text { excision, no } \\
\text { relapse }\end{array}$ \\
\hline 7 & $\begin{array}{l}\text { Hemiparesis, } \\
\text { Seizures }\end{array}$ & $\begin{array}{l}\text { Asleep-awake- } \\
\text { awake }\end{array}$ & $\begin{array}{l}\text { Hemiparesis and } \\
\text { seizures } \\
\text { resolved }\end{array}$ \\
\hline 8 & $\begin{array}{l}\text { Upper limb } \\
\text { paralysis, } \\
\text { seizures }\end{array}$ & $\begin{array}{l}\text { Asleep-awake- } \\
\text { awake }\end{array}$ & $\begin{array}{l}\text { Paralysis and } \\
\text { seizures } \\
\text { resolved with no } \\
\text { relapse of } \\
\text { symptoms }\end{array}$ \\
\hline
\end{tabular}

\section{Results}

None of our patients experienced any significant complications such as hemodynamic instability, depressed respiration, the need to put the patient to sleep before mapping or tumor resection was completed, intraoperative seizures, aspiration, and brain edema. 
The awake craniotomy is done mainly in supine position and involves manipulation of the frontal and parietal lobes, which therefore, causes the dural closure to be less painful in the aforementioned areas in comparison to basal parts of the brain. None of our patients experienced pain during closure of the dura.

Since excision of the pathologic area was done under close monitoring of the adjacent cortices, the cortical damage was avoided and patient motor abilities remained intact whilst the lesion excision was completed. In all patients the tumor/lesion was entirely resected and postoperative images were acceptable. The patients were discharged in a good general state after the operation.

The patients were awake during the last stage of surgery, which caused a fast-track transfer of patients to the intensive care and a rapid reanimation of patients, which then again contributed to the prompt discharge and minimal postoperative complications.

\section{Discussion}

The main purpose of using awake craniotomy is to provide a more accurate manner with which the procedure of resecting the area of interest in the brain is done, whether it is a tumor, or seizure focus. As for any type of procedure, it has both advantages and disadvantages.

The most prominent advantage, as said, is the ability to localize the area of interest, sparing the innocent uninvolved tissue; most importantly the motor and speech cortices. Other proposed advantages described, are a decrease in postoperative nausea and vomiting and the need for medication to control pain (23), a shorter hospital stay, less need for intensive care and fewer complications (1).

As described earlier, different methods for awake craniotomy surgeries have been in use, and to date there is no consensus on which method is superior. The three phases of the asleep-awake-asleep technique and awake craniotomy using local anesthesia and block of the sensory nerve supply to scalp, are the two main methods for awake craniotomy. The method we employed is a modification of the asleep-awake-asleep technique, in which the approach is changed to asleep-awake-awake. Because of the short half life of remifentanil, the combination of remifentanil and propofol provides convenient anesthesia with adequate control on the depth of anesthesia and a relatively rapid recovery after the infusion is discontinued. Several studies have compared different combinations of anesthetic techniques, including a mixture of volatile agents, a mixture of a volatile agent and an IV agent, and a mixture of two IV agents. In this regard, we only used intravenous anesthesia and avoided the inhalational anesthetics to avoid potential effects of volatiles on brain relaxation and nausea. Some have proposed more complications in a certain group (for example, increased hypotension with the use of sevoflurane (24)), while others have proposed no significant superiority for one over another (25). Recently, there is a tendency towards the short acting medications, which have less respiratory depressant effects, such as dexmedetomidine, which is an alpha-2 agonist with desired effects on hemodynamic indices and has shown to decrease bleeding in some neurosurgical and skull base surgeries (26). However, there are not enough prospective, controlled studies regarding this manner and a universal guideline cannot yet be introduced. Thus further research should be carried out.

\section{References}

1. Taylor MD, Bernstein M. Awake craniotomy with brain mapping as the routine surgical approach to treating patients with supratentorial intraaxial tumors: a prospective trial of 200 cases. J Neurosurg. 1999;90(1):35-41. doi: 10.3171/jns.1999.90.1.0035. [PubMed: 10413153].

2. Attari M, Salimi S. Awake craniotomy for tumor resection. Adv Biomed Res. 2013;2:63. doi: 10.4103/2277-9175.115815. [PubMed: 24223378].

3. Blanshard HJ, Chung F, Manninen PH, Taylor MD, Bernstein M. Awake craniotomy for removal of intracranial tumor: considerations for early discharge. Anesth Analg. 2001;92(1):89-94. [PubMed: 11133607].

4. Brown T, Shah AH, Bregy A, Shah NH, Thambuswamy M, Barbarite E, et al. Awake craniotomy for brain tumor resection: the rule rather than the exception? J Neurosurg Anesthesiol. 2013;25(3):240-7. doi: 10.1097/ANA.0b013e318290c230. [PubMed: 23603885].

5. Conte V, Baratta P, Tomaselli P, Songa V, Magni L, Stocchetti N. Awake neurosurgery: an update. Minerva Anestesiol. 2008;74(6):289-92. [PubMed: 18500200].

6. Gupta DK, Chandra PS, Ojha BK, Sharma BS, Mahapatra AK, Mehta VS. Awake craniotomy versus surgery under general anesthesia for resection of intrinsic lesions of eloquent cortex-a prospective randomised study. Clin Neurol Neurosurg. 2007;109(4):335-43. doi: 10.1016/j.clineuro.2007.01.008. [PubMed: 17303322].

7. Lanier WL. Brain tumor resection in the awake patient. Mayo Clin Proc. 2001;76(7):670-2. doi: 10.4065/76.7.670. [PubMed: 11444397].

8. Meyer FB, Bates LM, Goerss SJ, Friedman JA, Windschitl WL, Duffy JR, et al. Awake craniotomy for aggressive resection of primary gliomas located in eloquent brain. Mayo Clin Proc. 2001;76(7):677-87. doi: 10.4065/76.7.677. [PubMed: 11444399].

9. Sacko O, Lauwers-Cances V, Brauge D, Sesay M, Brenner A, Roux FE. Awake craniotomy vs surgery under general anesthesia for resection of supratentorial lesions. Neurosurgery. 2011;68(5):1192-8. doi: 10.1227/NEU.ob013e31820c02a3. [PubMed: 21273923].

10. Serletis D, Bernstein M. Prospective study of awake craniotomy used routinely and nonselectively for supratentorial tumors. J Neurosurg. 2007;107(1):1-6. doi: 10.3171/JNS-07/07/0001. [PubMed:17639865].

11. Bekker AY, Kaufman B, Samir H, Doyle W. The use of dexmedetomidine infusion for awake craniotomy. Anesth Analg. 2001;92(5):1251-3. [PubMed: 11323355].

12. Bilotta F, Rosa G. 'Anesthesia' for awake neurosurgery. Curr Opin Anaesthesiol. 2009;22(5):560-5. doi: 10.1097/ACO.ob013e3283302339. [PubMed: 19623055].

13. Dinsmore J. Anaesthesia for elective neurosurgery. $\mathrm{Br} J$ Anaesth 2007;99(1):68-74. doi: 10.1093/bja/aem132. [PubMed: 17573395].

14. Frost EA, Booij LH. Anesthesia in the patient for awake craniotomy. Curr Opin Anaesthesiol. 2007;20(4):331-5. doi: 10.1097/ACO.ob013e328136c56f. [PubMed: 17620841]. 
15. Hans P, Bonhomme V, Born JD, Maertens de Noordhoudt A, Brichant JF, Dewandre PY. Target-controlled infusion of propofol and remifentanil combined with bispectral index monitoring for awake craniotomy. Anaesthesia. 2000;55(3):255-9. [PubMed:10671844].

16. Johnson KB, Egan TD. Remifentanil and propofol combination for awake craniotomy: case report with pharmacokinetic simulations. J Neurosurg Anesthesiol. 1998;10(1):25-9. [PubMed: 9438615].

17. Rughani AI, Rintel T, Desai R, Cushing DA, Florman JE. Development of a safe and pragmatic awake craniotomy program at Maine Medical Center. J Neurosurg Anesthesiol. 2011;23(1):18-24. doi: 10.1097/ANA.ob013e3181ebf050. [PubMed: 20706142].

18. Sarang A, Dinsmore J. Anaesthesia for awake craniotomy-evolution of a technique that facilitates awake neurological testing. Br J Anaesth. 2003;90(2):161-5. [PubMed: 12538371].

19. Sung B, Kim HS, Park JW, Byon HJ, Kim JT, Kim CS. Anesthetic management with scalp nerve block and propofol/remifentanil infusion during awake craniotomy in an adolescent patient -A case report. Korean J Anesthesiol. 2010;59 Suppl:S179-82. doi: 10.4097/kjae.2010.59.S.S179. [PubMed: 21286435].

20. Huncke K, Van de Wiele B, Fried I, Rubinstein EH. The asleep-awakeasleep anesthetic technique for intraoperative language mapping. Neurosurgery. 1998;42(6):1312-6. [PubMed: 9632190] discussion 1316-7.

21. Bonhomme V, Franssen C, Hans P. Awake craniotomy. Eur J Anaes- thesiol. 2009;26(11):906-12. doi: 10.1097/EJA.0b013e32833000c5. [PubMed: 19617839]

22. Dreier JD, Williams B, Mangar D, Camporesi EM. Patients selection for awake neurosurgery. HSR Proc Intensive Care Cardiovasc Anesth. 2009;1(4):19-27. [PubMed: 23439673].

23. Manninen PH, Tan TK. Postoperative nausea and vomiting after craniotomy for tumor surgery: a comparison between awake craniotomy and general anesthesia. J Clin Anesth. 2002;14(4):279-83. [PubMed: 12088812].

24. Sneyd JR, Andrews CJ, Tsubokawa T. Comparison of propofol/remifentanil and sevoflurane/remifentanil for maintenance of anaesthesia for elective intracranial surgery. $\mathrm{Br} J$ Anaesth. 2005;94(6):778-83. doi:10.1093/bja/aei141. [PubMed: 15833780].

25. Magni G, Baisi F, La Rosa I, Imperiale C, Fabbrini V, Pennacchiotti ML, et al. No difference in emergence time and early cognitive function between sevoflurane-fentanyl and propofol-remifentanil in patients undergoing craniotomy for supratentorial intracranial surgery. $J$ Neurosurg Anesthesiol. 2005;17(3):134-8. [PubMed:16037733].

26. Salimi A, Sharifi G, Bahrani H, Mohajerani SA, Jafari A, Safari F, et al. Dexmedetomidine could enhance surgical satisfaction in Trans-sphenoidal resection of pituitary adenoma. J Neurosurg Sci. 2017;61(1):46-52. [PubMed: 24866894]. 